\title{
COBLATION ASSISTED CORDECTOMY FOR VERRUCOUS LESION OF BILATERAL VOCAL CORDS
}

\author{
Author: S. Pookamala* \\ Authors Affiliation: Assistant professor of ENT, Velammal medical college hospital and Research institute, \\ Madurai
}

\begin{abstract}
Verrucous lesions of vocal cord are irregular whitish lesion with papillomatous surface. In head and neck region, it commonly affects oral cavity and larynx. Laryngeal lesions cause hoarseness and breathing difficulty. Biopsy of the lesion is essential to look for malignancy. Early lesions are amenable for endoscopic resection. Endoscopic resection can be done with microlaryngeal instruments or using $\mathrm{CO} 2$ laser/coblator for precise resection. Here we discuss the role of coblator in endoscopic resection of verrucous lesion of vocal cords.
\end{abstract}

\section{KEYWORDS}

Coblation, Verrucous lesion of vocal cords, verrucous carcinoma

\section{INTRODUCTION}

Verrucous lesion of vocal cord refers to whitish irregular papillomatous lesions in vocal cords. It can be of benign or malignant in nature and biopsy is required to rule out malignancy. Biopsy of the lesion shows hyperkeratosis, parakeratosis with retepegs formation. Stromal invasion is seen in malignant lesions. Treatment options includes surgical resection and follow up. Surgical resection can be accomplished endoscopically in early and limited lesions using $\mathrm{CO} 2$ laser. In our case, we have done endoscopic resection using coblation laryngeal probe. This article highlights the role and advantage of coblation in endoscopic resection of laryngeal verrucous lesion.

\section{CASE REPORT}

66 year old gentleman presented to our OPD with symptoms of hoarseness for 6 months. He did not have any other associated symptoms like breathing difficulty, chronic cough, dysphagia, throat pain or weight loss. He did not have any medical co-morbidities or addiction habits. ENT examination revealed a whitish keratotic lesion involving superior and medial surface of both vocal cords. Mobility of vocal cords were normal and remaining area of larynx and hypopharynx were normal. Neck examination did not reveal

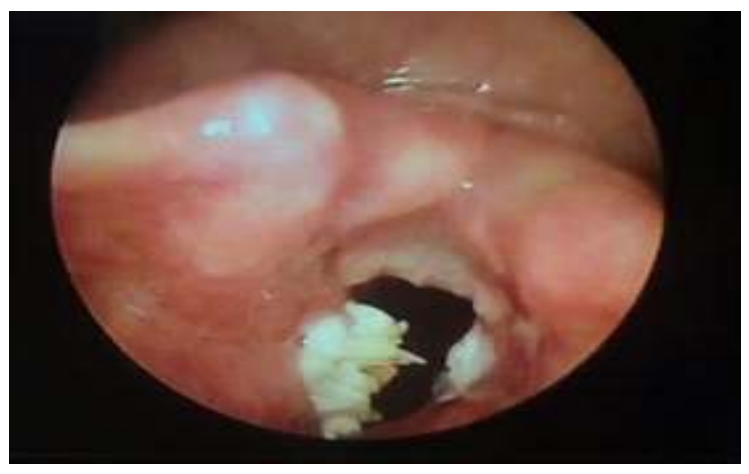

any cervical lymphadenopathy or Laryngeal expansion with preserve laryngeal crepitus.

Figure 1: Videolaryngoscopy showing keratotic lesion in bilateral vocal cords.

CT scan of neck showed irregularity at the level of vocal cords with no evidence of cartilage erosion or lymphadenopathy. Biopsy of the lesion was done under general anaesthesia and histopathological examination revealed a hyperkeratotic lesion with no evidence of invasion. 


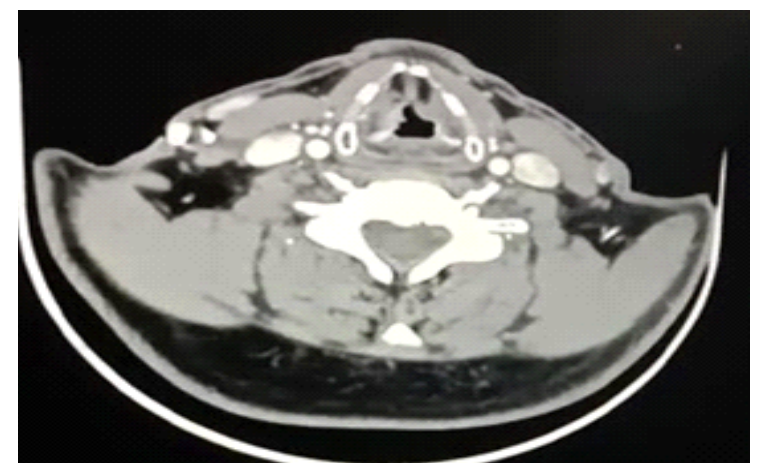

Figure 2: CT scan of neck showing irregularity at the level of vocal cords with no evidence of cartilage erosion.

He was taken up for repeat surgery after 2 weeks and excision biopsy of the lesion in both the cords were done. Repeat biopsy showed a hyperkeratotic lesion with retepegs formation and no evidence of invasion. He was kept under follow up. One month later, when he came for follow up he was found to have recurrent keratotic lesion in both vocal cords. He also developed recent onset exertional angina and cardiac workup showed coronary artery disease and he underwent coronary angioplasty and stenting for the same. In view of the histopathological findings and recurrent growth he was planned for Coblation assisted cordectomy after discussion with radiation oncologist and cardiologist.

Patient was taken up for surgery under general anaesthesia and intubation was done using flexometallic tube. Larynx was exposed using direct laryngoscope. Keratotic lesion in vocal cord was excised using coblation laryngeal probe (Smith \& Nephew Arthrocare ENT coblator). Dissection was done using ablation mode and bleeder was controlled using coagulation mode. Plane of resection is upto vocal ligament (similar to Type II cordectomy in TLM CO2 resection.). Resection included both the cord lesions and anterior commissure

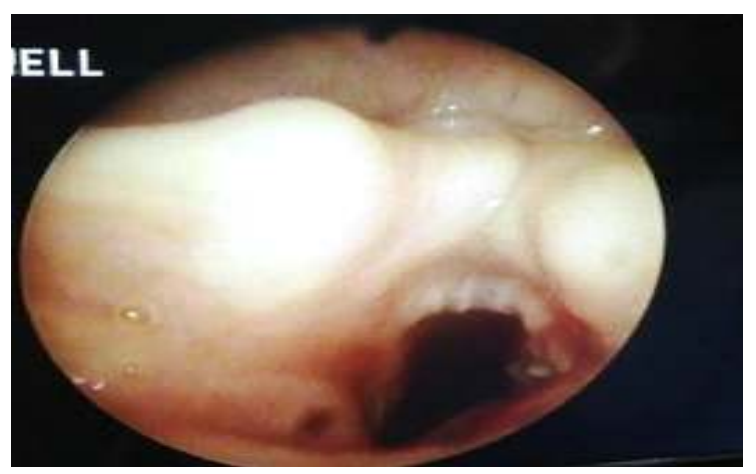

Figure 3: Post op endoscopy showing well healed mucosa with no evidence of recurrence. To prevent glottis web, Mitomycin C was applied over the anterior commissure area. Extubation was done soon after the procedure and he received steroids for 48 hours to prevent airway edema. He was kept under absolute voice rest and semi solid/ liquid diet for 1 week. He had mild aspiration for liquids which improved with swallow therapy. Final histopathology also did not reveal any invasive lesion. He was kept on regular follow up, he did not develop any recurrent lesion during the follow up period.

\section{DISCUSSION}

Verrucous lesions refers to whitish irregular lesion with papillomatous appearance, usually caused by HPV virus.They are seen commonly in oral cavity and larynx. In larynx, commonest site of involvement is vocal cords 1 . It commonly affects males with ahistory of smoking 2. Common clinical symptoms includes hoarseness, breathing difficulty and dysphagia. On endoscopy, these lesions appear as whitish exophytic growth with a papillomatous surface. Histopathology of the lesions reveal hyperkeratosis, parakeratosis, papillomatosis and bulbous retepegs pushing towards the stroma. Presence of stroma invasion indicates malignancy 3,4.Clinical and pathological differentiation from verrucous carcinoma is very difficult. Many a times repeated biopsy is required to rule out malignancy.

In our case, based on clinical appearance, he was diagnosed to have verrucous lesion of vocal cord and taken up for biopsy. Initial biopsy did not show any dysplasia or invasion and the repeat 
biopsy also did not show any stromal invasion but it was highly suspicious of malignancy. Near total excision of the lesion was done during the repeat surgery and he was kept under follow up.

Treatment options for verrucous lesions, both benign and malignant is total surgical excision and follow up1. Radiotherapy is not considered as an initial option for verrucous carcinoma of larynx as there is theoretical risk of anaplastic transformation with radiotherapy and local control after initial radiotherapy is very poor5. Surgical options include transoral laser microsurgical excision (TLM), partial or total laryngectomy depending upon disease extent. In our case, the lesion showed recurrence during 1 month follow up. The case was discussed with radiation oncologist and radiotherapy was not considered in view of his histopathology findings.So he was planned for surgery after obtaining cardiac and anaesthetist fitness. In our case, the lesion was confined to both the vocal cords with preserved cord mobility, hence planned for transoral excision. We used coblation probe for excision of vocal cord lesion instead of traditional $\mathrm{CO} 2$ laser system. Advantages of coblation includes, minimal bleeding, inbuilt suction port, precise cutting and less thermal damage. 6 The angulated tip makes dissection near anterior commissure and other narrow areas easier when compared to $\mathrm{CO} 2$ laser. Unlike CO2 laser, coblation is relatively cheaper and readily available in most of ENT centres. Availability and cost factor is a major issue with CO2 laser.

During the post op period, patient did not develop any complications like bleeding, airway edema or web formation. Post op voice quality is intelligible with no whispering or hoarseness. There was minimal aspiration for liquids, but it improved in 1 month with swallow therapy.There was no loco-regional recurrence.

\section{CONCLUSION}

Coblation assisted cordectomy can be safely done in pre-malignant or in selected early malignant lesions of vocal cords, with better voice, swallowing and oncologic outcome.

\section{REFERENCES:}

1) P.Strojan, L.Smid, CizmareviC, T.Zagar, M.Auersperg. Verrucous carcinoma of the larynx: Determining the best treatment option. European journal of surgical oncology Nov 2006;32;9:984-88.

2) Barnes L, Yunis EJ, Krebs FJ 3rd, SonmezAlpan E. Verruca vulgaris of the larynx. Demonstration of human papillomavirus types $6 / 11$ by in situ hybridization. Arch Pathol Lab Med 1991;115:895-9.

3) Fechner RE, Mills SE. Verruca vulgaris of the larynx: A distinctive lesion of probable viral origin confused with verrucous carcinoma. Am J SurgPathol 1982;6:357-62.

4) Anoopa M V, Anithakumari A M, Emmanuel R. Laryngeal verruca vulgaris: An unusual presentation. J Laryngol Voice 2020;10:15-7

5) Shao Hui Huang, Gina Lockwood, M. Math, Jonathan Irish, Jolie Ringash, Bernard Cummings et al. Truths and myths about radiotherapy for verrucous carcinoma of Larynx. Int. J. Radiation Oncology Biol. Phys., Vol. 73, No. 4, pp. 1110-1115, 2009.

6) Bing Liu, Liangjun Cheng, Hao Ming, Chang Zhong. Treatment of the early-stage glottis cancer using low-temperature radiofrequency Coblation. Journal of cancer research and therapeutics 2016;12;2:830-33.

\section{Source of Funding: None}

\section{Conflict of Interest: None}

\author{
*Address for correspondence: \\ Dr. S. Pookamala MS., DNB., \\ Assistant Professor of ENT, \\ Velammal medical college hospital and research \\ institute, \\ Madurai-625009. \\ Tamilnadu, India. \\ Email:pookamala@yahoo.com
}

